\title{
Assessing zeolite frameworks for noble gas separations through a joint experimental and computational approach
}

Keith V. Lawler ${ }^{1}$, Amit Sharma ${ }^{1}$, Breetha Alagappan ${ }^{1}$, Paul M. Forster ${ }^{1, *}$

\begin{abstract}
All 229 identified zeotype frameworks are screened in their siliceous form by grand canonical Monte Carlo simulation for their ability to separate a radiochemically relevant $\mathrm{Kr} / \mathrm{Xe}$ mixture in a pressure swing adsorption process. Prior to screening, our model was benchmarked against experimental single gas adsorption measurements, and it was found that for Kr and Xe a Lennard-Jones 9-6 potential with a softer repulsion than an equivalently parameterized LennardJones 12-6 potential was necessary to accurately model fluid-fluid interactions. Examination of the most promising candidate materials, we concluded that that zeolites with small, accessible cages about the size of a Xe atom performed the best initially. Zeolites with narrow pore channels with spots along the pore wall with high local surface area are the best performers across all loadings.

Keywords: Zeolites, Selectivity, Gas Adsorption, Gas Separation, Grand Canonical Monte Carlo
\end{abstract}

\section{Introduction}

Alongside activated carbons and metal-organic frameworks (MOFs), zeolites represent a major family of adsorbents critical to non-cryogenic gas separation technologies. 1, 2, 3, Zeolites have been shown to be useful in numerous separa-

\footnotetext{
* Corresponding author

Email address: Paul.Forster@unlv.edu (Paul M. Forster)

${ }^{1}$ University of Nevada Las Vegas, Department of Chemistry, Las Vegas, NV 89154-4003, USA
}

Preprint submitted to Microporous and Mesoporous Materials

September 29, 2015

(C) 2015. This manuscript version is made available under the Elsevier user license http://www.elsevier.com/open-access/userlicense/1.0/ 
5 tion applications, such as $\mathrm{CO}_{2} / \mathrm{CH}_{4}$, , 4, 5, 6, 17, 8, $\mathrm{N}_{2} / \mathrm{O}_{2},[9,10,11,12,13$, 13, and $\mathrm{CO}_{2} / \mathrm{N}_{2} \cdot[14,15,16,17,18,19,20$,

Our group is studying the non-cryogenic separation of $\mathrm{Kr}$ and $\mathrm{Xe}$ through pressure-swing adsorption (PSA) 21, 22] and related techniques. Development of a viable process has implications for in two separations of interest. The 10 first is the final separation of $\mathrm{Kr}$ and $\mathrm{Xe}$ from air; this mixture has a 80:20 $\mathrm{Kr}$ :Xe molar ratio after the noble gases have been isolated. The other process of interest is encountered during processing of spent radioactive fuel. [23, 24] Once all other gases are purged, noble gas fraction consists of 90:10 Xe:Kr. As Xe has no isotopes with half-lives longer than 30 days, Xe is expected to contain essentially no radioactive isotopes at the time of separation. In the $\mathrm{Kr}$ fraction however, some radioactive $\mathrm{Kr}^{85}$ is present. Storage of the entire mixture is impractical when only only the Kr fraction needs to be sequestered. In addition, this separation could serve as a new source for commercial Xe which has a very high cost $\$ 5000 / \mathrm{L}$ owing to it's rarity as a minor byproduct from cryogenic distillation of air. Cryodistillation is prohibitively expensive due to high cost and large space requirements associated with the necessary equipment, making PSA an attractive method to accomplish this separation.

Zeolites present several advantages for a practical separation compared to MOFs. A number of zeolite adsorbents are available commercially. The majority 25 of these are inexpensive, stable, less toxic, and well-characterized for large-scale use. In comparison to MOFs, zeolites tend to be more robust materials. This is a particularly useful trait when separating radiowaste that will constantly be emitting high energy decay particles that would damage or destroy most MOFs. The challenge for selecting a gas adsorbent among zeolites lies in determining which framework topology, composition, and extra-framework cation(s) provide ideal adsorption properties for the specific separation. Currently 229 topologies are recognized by the IZA. 25] While this number is much lower than for MOFs, most zeolites may be synthesized over a range of $\mathrm{Si} / \mathrm{Al}$ ratios and their adsorption properties may be further altered by ion exchange, leading to a very large 35 number of potential adsorbents. 
A purely experimental approach to searching for adsorbents is not optimal for several reasons. Assessing one specific zeolite is labor intensive in terms of synthesis, ion exchange, characterization, and extended gas adsorption analysis. Even when a zeolite is found to be promising, it is generally not clear from 40 the initial experimental data why that specific zeolite exhibits good selectivity without performing additional experiments such as in-situ crystallography with gas loading. Without an atomistic picture of gas adsorption, it is not straightforward to take a positive result for one adsorbent and use that information to select better adsorbents. Using modelling techniques such as grand canonical Monte Carlo (GCMC), an atomistic picture of adsorption can be acquired which leads to an understanding of the adsorption behavior in materials known to perform well for certain separations, guiding the search for better adsorbents.

Recent work on heavy noble gas separations by our group and others have previously studied MOF materials for $\mathrm{Kr} / \mathrm{Xe}$ separation. Across a range of 50 MOFs, large selectivities are consistently associated with smaller pores or pockets of comparable size to Xe. [26, 27, 28, 29, 30, 31, 32, 33, 34, 35, 36, 37, 38, 39. From this observation, we were able to target structures with such adsorption sites for study, and determined that a family of porous transition $\alpha$-metal formates show both reasonable capacity and consistently high selectivities over a wide range of loadings. [36] Recently, an impressive screening study was performed that screened 670,000 different known and hypothetical porous zeolites, MOFs, ZIFs, PPNs, and COFs for their selectivity at an initial loadings of an 20:80 mixture of Xe:Kr at room temperature. 40. Their results supported the conclusion that topologies with smaller pores and pockets that maximized interaction with Xe had improved Xe selectivities, and one of their top performers is SIZ-3 (CSD code: JAVTAC) which is an AlPO-11 (AEL) zeolite analogue. 41.

Zeolites exist across a range of compositions with the simplest possible form containing only $\mathrm{Si}$ and $\mathrm{O}$. A significant number of zeolites have been synthesized in either purely siliceous forms, or very high silica compositions where the

${ }_{65}$ siliceous form would provide a reasonable approximation of the zeolite's behavior. While siliceous zeolites are a natural point to begin modelling efforts, they 
may well represent practical adsorbents as well. Since they are hydrophobic, they are particularly stable and robust, may be activated and reactivated under simple conditions, and are relatively tolerant to trace water during separations. As adsorbents, they may offer good selectivity through dispersive interactions for Kr and Xe, which have no standing multipolar moments to strongly interact with cations. In contrast, the separation of $\mathrm{N}_{2}$ and $\mathrm{O}_{2}$ is best done in zeolites with small, highly charged cations ( $\mathrm{Li}, \mathrm{Mg}, \mathrm{Ca}$ ) because of the four-fold difference in standing quadrupole moment of the two gases.

A vital part of studying $\mathrm{Kr} / \mathrm{Xe}$ adsorption in the vast family of zeolites is developing a transferable description of adsorption into the pure $\mathrm{TO}_{2}$ frameworks. Here we develop such a model which we show can generally predict gas adsorption isotherms to excellent agreement with experiment. We then apply the model to all 229 siliceous zeolites to determine their ability to separate 90:10

80 Xe:Kr across the range of loadings relevant to an actual PSA process.

\section{Experimental}

We obtained a sample of calcined and activated siliceous LTA (ITQ-29) from Avelino Corma's group. 42] We obtained a sample of siliceous FAU from Joseph Hriljac. 43 We obtained a sample of siliceous BEA from Dr. Laszlo Nemeth that was synthesized, calcined, activated, and characterized using a modification of a previously published procedure with tetraethylorthosilicate as the only silica metal source. 44] About $150 \mathrm{mg}$ of each sample was initially activated under dynamic turbopump vacuum at $400{ }^{\circ} \mathrm{C}$ for 24 hours. Gas adsorption isotherms were measured according to our previously published procedure 35] using a Micromeritics ASAP 2020 instrument fitted with a He cryostat with a stability of better than $\pm 0.01 \mathrm{~K}$. Isotherms were collected up to $\sim 710 \mathrm{mmHg}$ with 5 $\mathrm{cm}^{3} / \mathrm{g}$ incremental volumetric doses and long equilibration times. Desorption measurements were taken at the end of each isotherm. Each measurement displayed negligible hysteresis, indicating equilibrium had been achieved. Samples were reactivated for an hour under dynamic vacuum at $150{ }^{\circ} \mathrm{C}$ and allowed to 
equilibrate in the cryostat for an hour between each measurement. Kr isotherms were measured at $230 \mathrm{~K}, 240 \mathrm{~K}$, and $250 \mathrm{~K}$. Xe isotherms were measured at 280 $\mathrm{K}, 290 \mathrm{~K}$, and $300 \mathrm{~K}$. The Clausius-Clapeyron equation was used to obtain isosteric heats of adsorption.

\subsection{GCMC Details}

Gas adsorption was simulated with Monte Carlo in the grand canonical ensemble using the multi-component Peng-Robinson equation of state for fugacities. 45 , 46, 47, 48, GCMC simulations were done with a modified version of the MUSIC package. [49] The binary mixing parameters are found using the form of Coutinho et al. [50] In addition to the normal GCMC moves, a swap and exchange moves were moved to improve equilibration in the binary gas simulations. [51, 52, 53. Each simulation employed 200,000 equilibration cycles and 300,000 production cycles. A cycle here consists of $\mathrm{N}$ moves, where $\mathrm{N}$ is the number of adsorbed particles (minimum 20). The zeolites are held as rigid during the simulations.

We carefully considered potential options for obtaining crystal structures for the 229 zeolites. While experimental structures are attractive in some respects, they are not available for the majority of $\mathrm{SiO}_{2}$ zeolites, and vary in accuracy. For a comparative screening effort, we anticipate that a self-consistent set of structures would provide the best means of comparing zeolitic topologies directly. Computational lattice energy minimization is particularly well-developed in the case of $\mathrm{SiO}_{2}$ zeolites, and should provide reasonably accurate structures that are fully self-consistent with each other. We used structures taken from the IZA-SC Database of Zeolite Structures. 25] Those structures were optimized using the DLS76 program for a pure $\mathrm{SiO}_{2}$ composition in a pre-dominant symmetry of the zeolite. Some of the frameworks (CHI, CLO, EWT, IRY, ITN, ITV, LIT, PAR, RON, SSO, SVR, and WEN) are acknowledged by the IZA-SC as interrupted frameworks that cannot be made as four-connected frameworks (stoichiometrically $\mathrm{SiO}_{2}$ ) and therefore have dangling oxygens around the broken tetrahe- 
dra. For these frameworks, Olex2 was used to place the hydrogens to form silanol groups to terminate the dangling oxygens which would be the calcined form of the framework. [54] The hydrogen positions in the primitive cell were refined with a selective dynamics plane-wave density functional theory [55, 56] optimization with the Vienna ab-initio Simulation Package 5.3.5 (VASP) using the projector-augmented wave (PAW) [57] method and the generalized gradient approximation (GGA) exchange-correlation functional of Perdew, Burke, and Ernzerhof (PBE). [58] Just the $\Gamma$ point was used to describe k-space. The WEN structure in the database does not include the experimental disorder and omits two of the would be silanol oxygens. To solve this, we constructed both symmetry inequivalent forms of the originally reported WEN experimental crystal structure, and the lower energy 'trans' form is used in the screening. [59]

*** Table 1 about here $* * *$

The internal energy was found using the following energy expression: $U=$ $\mathrm{U}_{\text {framework-fluid }}+\mathrm{U}_{\text {pol }}+\mathrm{U}_{\text {fluid-fluid }}$. Table 1 includes all of the single species 40 parameters used in this work. The framework-fluid potential was computed using a 12-6 Lennard-Jones with a low cutoff of $1.5 \AA$ and a high cutoff at $15 \AA$. The atomic parameters for the framework-fluid potential are from the first two sections of table 1 and combined using the Lorentz-Berthelot mixing rules. The framework $\mathrm{Si}$ and $\mathrm{O}$ parameters come from the recently developed ${ }_{145}$ TraPPE-zeo forcefield, 60] and the silanol hydrogen parameters are taken from ClayFF with the charge lowered to ensure charge neutral unit cells. 61] The Kr and Xe parameters were found using the principle of corresponding states using the Ar parameters of Talu and Myers 62 and the critical parameters from the CRC 63] as the starting point. Explicit fluid point dipole polarizability was included as " $\mathrm{U}_{\text {pol }}$ " using the polarizability volumes in table 1, 1] The electric field is computed with the Wolf Coulomb potential truncated at $15 \AA$, a damping parameter of $0.1 \AA^{-1}$, and both the force and potential shifted. 64, 65, 66, 67] In our own experiments, we have found that high loading regimes of isotherms for Kr and Xe are better modeled with a 9-6 Lennard-Jones potential, therefore the fluid-fluid potential interactions were modeled with the 9-6 fluid COMPASS 68. 
force field (last section of table 1 cutoff at $15 \AA$ and combined with $6^{\text {th }}$ order mixing rules.

\subsection{Mapping the pore volume}

In zeolites there are pores that are known experimentally to be accessible to guests while there are cages that are kinetically inaccessible. To correctly model the accessible volume within a zeolite, we developed our own void volume mapping program which is very similar to a recently developed program. 69] Our program lays down a uniform grid of parallelpiped voxels laid in each crystallographic dimension, evaluates the energy of the adsorbate-framework Lennard-

Jones interaction for the center of each voxel, and uses a six way (no diagonal connections) 3-D flood fill algorithm connecting neighboring points that allows for the crossing of periodic boundaries. If a voxel has an energy below a certain threshold it is initially considered accessible and could be connected to other voxels; otherwise it is considered as belonging to the volume of the framework and could not be connected to other voxels. A void was determined to be part of a pore network if a path within the connected void volume made from 0 to 1 along any crystallographic dimension including crossing other dimension's PBCs, if no such path could be made that connected volume was considered a closed-off cavity. Our pore volumes are taken as the sum of the volume of all accessible parallelpipeds. We found that a grid spacing of $0.15 \AA$ and an energy cutoff of $+14 \mathrm{kcal} / \mathrm{mol}$ was sufficiently small to close off all CBUs that should be considered inaccessible. The pores produced in this manner have accessible pore volumes that typically agree to within $0.5 \%$ of those presented in the IZA-SC database. 70]

The GCMC moves were modified to have an auxiliary move rejection for use with the void maps. If the move placed the center of mass of the particle in a voxel within an open pore, the move is accepted by the conventional Metropolis algorithm. If the voxel is not part of an open pore, then the GCMC program checks whether the voxel is less than a certain number of voxels away (including diagonally). If any of the checked voxels are open, the move is accepted by the 
conventional Metropolis algorithm; otherwise the move is outright rejected. We used a depth of 3 voxels away to resemble a translation move that has walked the particle into the wall of a framework.

\section{Results and Discussion} the fluid-fluid interactions.

*** Figure 2 about here *** 
BEA is known to be polymorphic, and we only performed simulations using the structure of polymorph $\mathrm{A}$, the most representative polymorph. Given the similarity between the BEA polymorphs, we did not anticipate large differences with this approximation, as confirmed by the close agreement encountered. FAU is known to be a difficult material to produce in its siliceous form, as the process require dealumination and can lead to mesoporosity and aggregates of amorphous silica. This FAU sample seems to be high quality as a $77 \mathrm{~K} \mathrm{~N} \mathrm{~N}_{2}$ pore size distribution (over the default range in the Micromeritics software) is trimodal, which is in line with the three primary topological features of FAU: the $\alpha$ cage (t-fau), sod(t-toc) the sodalite or $\beta$ cage, and d6r (t-hpr) connecting the sodalite cages. The agreement between the FAU HOAs is of comparable quality to that of LTA and BEA, however the simulation model under-predicts total adsorption by $5-10 \%$. We believe the discrepancy arises from two factors: the mass of the measured sample being too low giving too high measured quantities adsorbed, and the COMPASS fluid-fluid parameters being too weak as FAU is a large pore system where correctly describing fluid-fluid interactions will be more critical.

*** Figure 3 about here $* * *$

The finalized model we employed yields excellent agreement for the isotherm and heat of adsorption for both gases at all tested temperatures. The predicted and measured heats of adsorption are both fairly flat, as expected of the rela235 tively homogenous surface inside these zeolites. What is surprising is the similarity of the predicted heats of adsorption for $\mathrm{Kr}$ and Xe in both materials. A lack of small accessible pockets in the cells and a surface covered in 4-ring to 6-ring provides an easy explanation for the flatness and similarities in the heats of adsorption between these materials. The difference in heat of adsorption is consistent across all loadings which we have shown indicates a fairly uniform $\mathrm{Xe} / \mathrm{Kr}$ selectivity at all loadings will be observed. We recognize that our approach neglects structural changes in response to gas uptake, as are known to occur in MFI, for example. [72, 73] However, the initial selectivities obtained from our calculations should still be valid. 


\subsection{Screening the zeolites}

We carried out our screening at $298 \mathrm{~K}$ at five pressures on a logarithmic scale spanning the Henry's law region $(1 \mathrm{mmHg})$ to PSA useful pressures $(10,000$ $\mathrm{mmHg}$ ). In table 1 of the Supplementary Information, we plot 1) the percent accessible pore volume of the framework, 2) the total loading at each point, 3) and the $\mathrm{Xe} / \mathrm{Kr}$ selectivity at each point.

*** Figure 4 about here $* * *$

Figures 4 and 5 summarize the screening results for both the initial adsorption $(1 \mathrm{mmHg})$ and high loading $(10,000 \mathrm{mmHg})$. The selectivities presented are for Xe over $\mathrm{Kr}$, and the material's percent accessible pore volume is used to shade the plotted points. In figure 4 a strong correlation between total loading and selectivity is evident, persisting to high loadings although with considerably more scatter. At low loadings, quantity adsorbed is primarily determined by the affinity of the zeolite for noble gases - frameworks with high HOAs for $\mathrm{Kr}$ and Xe also tend to have high selectivities. It is promising that zeolites with the highest selectivities tend to have relatively high adsorption for $\mathrm{Kr}$ and $\mathrm{Xe}$ as well. It is noteworthy that 10 zeolites have selectivities in excess of 10 - a value comparable to the most promising MOFs studied so far. At higher pressures, the zeolites stratify dramatically, as can be seen in figure 5. The zeolites with relatively low capacity $\left(20-60 \mathrm{~cm}^{3} / \mathrm{g}\right)$ tend to be the most selective which is mainly due to a narrow small pore system. The zeolites with large capacity $\left(\geq 100 \mathrm{~cm}^{3} / \mathrm{g}\right)$ are only moderately selective $(\sim 4$, the same as observed for HKUST-1 at high loadings). This is to be expected for large pore systems as they have space to accommodate large amounts of noble gas, but most of that gas cannot come into close enough contact with the unique framework topologies that provide sufficient dispersive interactions and to make the material selective.

*** Figure 5 about here ${ }^{* * *}$

For some separations, a selectivity in favor of $\mathrm{Kr}$ is desirable. A recent review of MOF applicability to this problem highlighted $\mathrm{FMOFCu}$, which could go from being Xe selective to $\mathrm{Kr}$ selective by lowering the temperature below $275 \quad 0{ }^{\circ} \mathrm{C}$. 74 A few siliceous zeolites appear selective for $\mathrm{Kr}$ (Xe/ $\mathrm{Kr}$ selectivity 
less than 1), but none appear practical overall. At $298 \mathrm{~K}$, four Kr-selective materials exhibited reasonable total gas loadings $\left(\geq 40 \mathrm{~cm}^{3} / \mathrm{g}\right)$, yet they are only slightly selective for Kr. More selective frameworks all have low porosity and either modest uptake or low Kr selectivity at the highest pressures measured. $(250 \mathrm{~K})$, were performed to see if the loadings of the $\mathrm{Kr}$ selective materials could be improved. Table 2 shows the results for quantity adsorbed and $\mathrm{Kr}$ selectivity at the highest loading point $(10,000 \mathrm{mmHg})$ for both temperatures evaluated. When cooled, the quantity adsorbed improved by no more than a factor of 5 for each of the zeolites examined. The Kr selectivity did not change appreciably for any materials with reasonable loadings. Remarkably high $\mathrm{Kr}$ selectivity is suggested in several topoligies, including CHI and NPO, but the predicted total uptake is so small that these materials would be impractical for applications. Our simulations strongly suggest no siliceous zeolites would be competitive with FMOFCu.

*** Table 2 about here ***

Figure 6] shows a strong correlation between the initial selectivities compared against the difference in the Xe and Kr heats of adsorption into the material. The heats of adsorption were computed with multi-component fluctuation theory. [75] There appears to be a maximal initial selectivity possible for a given difference in initial HOA, although many materials show lower selectivities than this. Normalizing the difference in heat of adsorption to either the $\mathrm{Kr}$, Xe, or total heat of adsorption does not yield a more linear or tightly correlated data set. The same effect is observed at all loadings with a similarly narrow spread in the results. This plot directly demonstrates the established rule of thumb for using single gas adsorption measurements to estimate a material's selectivity. Figure 6 indicates that, for a material to have a Xe selectivity $\geq 10$, the difference in heat of adsorption needs to be at least $\geq 8 \mathrm{~kJ} / \mathrm{mol}$.

*** Figure 6 about here $* * *$

Compiling the most selective materials at the both initial and high loadings, we selected 23 frameworks for more detailed study: AFO, ATN, ATO, BOF, 
CAN, CDO, EAB, EDI, EON, EPI, ESV, FER, LAU, LTF, MAZ, MRE, MTF, OFF, OWE, PCR, PSI, UFI, and ZON (those in bold are among the most selective at both initial and final loading). Examining these structures, we

ilar overall behavior generally occurs when several adsorption sites are present, 
especially with the sites are chemically similar. 8-ring pores are common in this group with examples of cylindrical, elliptical or zig-zag cross sections. 10-ring pores tend to be distorted. The zeolites EPI, ESV, MTF, and OWE show falloffs in selectivity at high loadings. OWE and EPI are 2-dimension materials with limited wall surface for adsorption whereas ESV and MTF have undulating pore volumes that resemble a series of pockets connected by smaller windows. As these features saturate, the decrease in selectivity is observed.

The second category of topological features leading to high selectivity are small pockets or secondary pores connected to larger pores. Features comparable in size to Xe provide a region with very high dispersive interactions favoring Xe. We have previously shown that this is the mechanism behind high initial HOAs and selectivities for $\mathrm{Kr}$ and Xe in HKUST-1, but that it also leads to lower HOAs and selectivities at higher loadings. In our survey, this mechanism leads to the highest initial selectivities, but these may not be ideal adsorbents for PSA-type processes as the selectivities drop as loading increases. We illustrate this mechanism with UFI, which has the highest predicted initial selectivity for siliceous zeolites. UFI has a $2 \mathrm{D}$ pore system consisting of large lta cages connected through 8-ring pores. A number of t-ufi cages are accessible through this pore system; this is where the simulations show gas density building up at low loadings (figure 8). This is analogous to the mechanism for high initial selectivity observed in HKUST-1. 35.

Figure 9 shows the results from the more thorough selectivity simulations for each of the top zeolites as a function of percent loading, with $100 \%$ defined as the respective loading at $10,000 \mathrm{mmHg}$. As all of the simulated adsorption data has been corrected to reflect the excess adsorption, a turnover in the isotherm should be expected when the density of the adsorbed fluid very closely matches that of the bulk fluid. [76] By collecting some data points beyond 10,000 $\mathrm{mmHg}$, we have determined that this turnover occurs around $10,000 \mathrm{mmHg}$ in almost all of these zeolites thus indicating the loading at $10,000 \mathrm{mmHg}$ is close to the 
asymptotic limit. The results have been divided into two sets corresponding to over useful loading ranges are most promising with narrow pore zeolites, these zeolites may also show much lower adsorption/desorption kinetics compared with zeolites containing larger pores and selective pockets. EAB represents a 
potentially important framework as it has both large channels, which should lead to superior kinetics, and also flat selectivity at all loadings. Further experimental studies are needed to determine whether these zeolites would be practical in real-world separations.

We are also well-aware that most zeolite frameworks have not been synthesized in purely siliceous forms. To our surprise, a number of zeolites do exhibit selectivities that are competitive with the best MOF adsorbents studied so far. One of the promising structures to emerge from this effort is FER, which is well-known in a pure silica form. Other frameworks (e.g. MRE, UFI) occur in high $\mathrm{Si} / \mathrm{Al}$ ratios, as germanosilicates (e.g. PCR), or as an AlPO (e.g. ATO, ZON), where performance may be comparable to the pure silica form. The promising germanosilicates and pure AlPO results here should be transferable as they have no mobile cations, the dispersion interactions should be similar(especially if the T-atom approximation is made), and the distribution of framework partial charges will have little effect on the adsorption of noble gases 45 as polarizability only accounted for $1-2 \%$ of the total energetics in this study (owing to the cancellation of electric fields caused by neighboring charges). Additionally, H-exchanged versions of these frameworks are likely to offer similar overall performance. Even in cases where compounds resembling the $\mathrm{SiO}_{2}$ form do not exist, such frameworks remain promising for follow-up studies where mobile cations are present. A final substantial advantage that siliceous zeolites have over aluminosilicates is that they are sufficiently hydrophobic that separations could be run in the presence of humidity without need for periodic reactivation.

The screening results presented here are a first step towards screenings with cations present. For realistic results from such screenings, cation mobility must be included, which represents a considerable challenge on its own. Good agreement between our experimental and simulated data on several $\mathrm{SiO}_{2}$ structures provides important validation that our model is indeed sufficiently accurate. The screening has also provided important clues as to which frameworks may be promising as cations are included in later simulations. Finally, in order to cor30 relate our results with the recent study by Smit, [40 we compared our predicted 
performance for air separation $(\mathrm{Xe} / \mathrm{Kr}=20: 80)$ to results for the radiochemical separation. The Xe selectivities remained comparable, except in compounds showing high selectivity due to small pockets, where the high loading selectivity greatly improved for the 20:80 ratio. Figures are presented in the SI.

\section{Conclusions}

An initial screening demonstrated that many siliceous zeolites have promise for a $\mathrm{Kr} / \mathrm{Xe}$ separation. In the case of EAB, EON, LTF, MAZ, OFF and UFI, a high initial selectivity results from the presence of a small cage off of the main pore system that is about the right size to adsorb a single Xe atom. However these small cages quickly saturate with increased gas loading. Zeolites with only small cages are expected to have limited utility as practical PSA sorbents as their selectivity is limited by the adsorption into the small cages. The most promising zeolites for selective Xe adsorption at PSA relevant pressures were ones that contained narrow pore systems with either zig-zags or elliptical cross MRE, and PSI as they have selectivities greater than 10 at all loadings and high capacities. CDO, FER, MRE, and MTF are of particular interest as these frameworks can be made as pure $\mathrm{SiO}_{2}$. AFO, ATO, PSI, and ZON are also of interest as they can be made as pure AlPOs to test the transferability of the pure silica results.

It is also important to note that a good parametrization of the force field is essential to using multi-component GCMC as a screening tool. TraPPE-zeo provides an excellent transferable description of fluid-framework interactions. The fluid-fluid interactions need to be correctly modeled to get good isothermal agreement at both low and high loadings, in particular for $\mathrm{Kr} / \mathrm{Xe}$ a softer repulsion term than that of a 12-6 Lennard-Jones is needed. This problem is not unique to this work, and can be seen in many of the previously published $\mathrm{Kr} / \mathrm{Xe}$ adsorption isotherms into MOFs and zeolites. In the future, we intend to extend our findings to some of the more complex zeolitic topolgies, i.e. cation 
containing aluminosilicates, and to include framework flexibility to better describe materials known to distort on adsorption like MFI.

\section{Acknowledgments}

This work was supported by the Department of Energy, Office of Nuclear Energy through a grant under the Nuclear Energy University Programs (NEUP). The loading density plots were made with the VESTA program. [77] We would like to thank Prof. Avelino Corma for providing us a sample of ITQ-29, Dr. Laszlo Nemeth for providing us a sample of siliceous BEA, and Prof. Joseph Hriljac for providing us a sample of siliceous FAU.

\section{References}

[1] J.-R. Li, R. J. Kuppler, H.-C. Zhou, Selective gas adsorption and separation in metal-organic frameworks, Chem. Soc. Rev. 38 (5) (2009) 1477-1504. doi:10.1039/B802426J.

[2] J.-R. Li, J. Sculley, H.-C. Zhou, Metal-organic frameworks for separations, Chem. Rev. 112 (2) (2012) 869-932. doi:10.1021/cr200190s.

[3] P. K. Thallapally, J. W. Grate, R. K. Motkuri, Facile xenon capture and release at room temperature using a metal-organic framework: a comparison with activated charcoal, Chem. Commun. 48 (3) (2012) 347-349. doi:10.1039/C1CC14685H.

[4] M. Palomino, A. Corma, F. Rey, S. Valencia, New insights on co2-methane separation using lta zeolites with different si/al ratios and a first comparison with mofs, Langmuir 26 (3) (2009) 1910-1917. doi:10.1021/la9026656.

[5] M. Palomino, A. Corma, J. L. Jordá, F. Rey, S. Valencia, Zeolite rho: a highly selective adsorbent for co2/ch4 separation induced by a structural phase modification, Chem. Commun. 48 (2012) 215-217. doi:10.1039/ C1CC16320E, 
[6] J. Kim, A. Maiti, L.-C. Lin, J. K. Stolaroff, B. Smit, R. D. Aines, New materials for methane capture from dilute and medium-concentration sources, Nat. Commun. 4 (2013) 1694. doi:10.1038/ncomms2697.

[7] L. Ohlin, P. Bazin, F. Thibault-Starzyk, J. Hedlund, M. Grahn, Adsorption of co2, ch4, and h2o in zeolite zsm-5 studied using in situ atrftir spectroscopy, J. Phys. Chem. C 117 (33) (2013) 16972-16982. doi: $10.1021 / j p 4037183$

[8] F. Gholipour, M. Mofarahi, Gas adsorption separation of co2/ch4 system using zeolite 5a, Microporous Mesoporous Mater. 200 (2014) 1-10. doi: 10.1016/j.micromeso.2014.08.022.

[9] S. P. Nandi, P. L. Walker Jr., Separation of oxygen and nitrogen using 5a zeolite and carbon molecular sieves, Sep. Sci. Technol. 11 (5) (1976) 441-453. doi:10.1080/01496397608085334.

[10] J. Cejka, H. van Bekkum, A. Corma, F. Schueh, Introduction to Zeolite Molecular Sieves, Elsevier, 2007.

[11] P. Li, F. H. Tezel, Adsorption separation of n2, o2, co2 and ch4 gases by

1 $\quad \beta$-zeolite, Microporous Mesoporous Mater. 98 (1-3) (2007) 94-101. doi: 10.1016/j.micromeso.2006.08.016.

[12] H. Karge, J. Weitkamp (Eds.), Molecular Sieves: Science and Technology, Vol. 7, Springer, 2008.

[13] V. J. Inglezakis, A. A. Zorpas (Eds.), Handbook of Natural Zeolites, Bentham Science, 2012.

[14] E. D. Akten, R. Siriwardane, D. S. Sholl, Monte carlo simulation of singleand binary-component adsorption of $\mathrm{co} 2, \mathrm{n} 2$, and h2 in zeolite na-4a, Energy Fuels 17 (4) (2003) 977-983. doi:10.1021/ef0300038.

[15] R. Siriwardane, M.-S. Shen, E. P. Fisher, Adsorption of co2, n2, and o2 on natural zeolites, Energy Fuels 17 (2003) 571-576. doi:10.1021/ef0201351. 
[16] M. P. Bernal, J. Coronas, M. Menéndez, J. Santamariá, Separation of co2/n2 mixtures using mfi-type zeolite membranes, AIChE J. 50 (1) (2004) 127-135. doi:10.1002/aic.10012.

[17] X. Gu, J. Dong, T. M. Nenoff, Synthesis of defect-free fau-type zeolite membranes and separation for dry and moist co2/n2 mixtures, Ind. Eng. Chem. Res. 44 (4) (2005) 937-944. doi:10.1021/ie049263i.

[18] E. García-Pérez, J. B. Parra, C. O. Ania, A. García-Sánchez, J. M. van Baten, R. Krishna, D. Dubbeldam, S. Calero, A computational study of co2, n2, and ch4 adsorption in zeolites, Adsorption 13 (2007) 469-476. doi:10.1007/s10450-007-9039-z.

[19] B. Liu, B. Smit, Comparative molecular simulation study of co2/n2 and ch4/n2 separation in zeolites and metal-organic frameworks, Langmuir 25 (10) (2009) 5918-5926. doi:10.1021/la900823d.

[20] M. Fischer, R. G. Bell, Influence of zeolite topology on co2/n2 separation behavior: Force-field simulations using a dft-derived charge model, J. Phys. Chem. C 116 (50) (2012) 26449-26463. doi:10.1021/jp3099768.

[21] R. T. Yang, Adsorbents: Fundamentals and Applications, Wiley, Hoboken, NJ, 2003. doi:10.1002/047144409X.

[22] S. Sircar, Basic research needs for design of adsorptive gas separation pro口 cesses, Ind. Eng. Chem. Res. 45 (16) (2006) 5435-5448. doi:10.1021/ ie051056a.

[23] J. Izumi, Waste gas treatment using zeolites in nuclear-related indus535 tries, in: S. Auerbach, K. Carrado, P. Dutta (Eds.), Handbook of Ze-

a olite Science and Technology, Marcel Dekker, New York, 2003. doi: 10.1201/9780203911167.ch20.

[24] N. R. Soelberg, T. G. Garn, M. R. Greenhalgh, J. D. Law, R. Jubin, D. M. Strachan, P. K. Thallapally, Radioactive iodine and krypton control for 
nuclear fuel reprocessing facilities, Sci. Technol. Nucl. Install. 2013 (2013) 702496. doi:10.1155/2013/702496

[25] International zeolite association-structure commission database of zeolite structures [cited June 5, 2014].

URL http://www.iza-structure.org/databases/

[26] U. Mueller, M. Schubert, F. Teich, H. Puetter, K. Schierle-Arndt, J. Pastre, Metal-organic frameworks - prospective industrial applications, J. Mater. Chem. 16 (7) (2006) 626-636. doi:10.1039/B511962F

[27] R. Bazan, M. Bastos-Neto, A. Moeller, F. Dreisbach, R. Staudt, Adsorption equilibria of $\mathrm{o} 2$, ar, $\mathrm{kr}$ and xe on activated carbon and zeolites: single component and mixture data, Adsorption 17 (2010) 371-383. doi:10. 1007/s10450-011-9337-3.

[28] P. Ryan, O. K. Farha, L. J. Broadbelt, R. Q. Snurr, Computational screening of metal-organic frameworks for xenon/krypton separation, AIChE J. 57 (7) (2011) 1759-1766. doi:10.1002/aic.12397.

[29] B. J. Sikora, C. E. Wilmer, M. L. Greenfield, R. Q. Snurr, Thermodynamic analysis of $\mathrm{xe} / \mathrm{kr}$ selectivity in over 137,000 hypothetical metal-organic frameworks, Chem. Sci. 3 (7) (2012) 2217-2223. doi:10.1039/C2SC01097F.

[30] T. Van Heest, S. L. Teich-McGoldrick, J. A. Greathouse, M. D. Allendorf, D. S. Sholl, Identification of metal-organic framework materials for adsorption separation of rare gases: Applicability of ideal adsorbed solution theory (iast) and effects of inaccessible framework regions, J. Phys. Chem. C 116 (24) (2012) 13183-13195. doi:10.1021/jp302808j.

[31] J. Liu, P. K. Thallapally, D. M. Strachan, Metal-organic frameworks for removal of xe and kr from nuclear fuel reprocessing plants, Langmuir 28 (31) (2012) 11584-11589. doi:10.1021/la301870n. 
[32] C. A. Fernandez, J. Liu, P. K. Thallapally, D. M. Strachan, Switching kr/xe selectivity with temperature in a metal-organic framework, J. Am. Chem. Soc. 134 (22) (2012) 9046-9049. doi:10.1021/ja302071t.

[33] M. Parkes, C. Steiger, J. Perry, IV, M. Allendorf, J. Greathouse, Screening metal-organic frameworks for selective noble gas adsorption in air: effect of pore size and framework topology, Phys. Chem. Chem. Phys. 15 (2013) 9093-9106. doi:10.1039/c3cp50774b.

[34] Y.-S. Bae, B. G. Hauser, Y. J. Colon, J. T. Hupp, O. K. Farha, R. Q. Snurr, High xenon/krypton selectivity in a metal-organic framework with small pores and strong adsorption sites, Microporous Mesoporous Mater. 169 (2013) 176-179. doi:10.1016/j.micromeso.2012.11.013.

[35] Z. Hulvey, K. V. Lawler, Z. Qiao, J. Zhou, D. Fairen-Jimenez, R. Q. Snurr, S. V. Ushakov, A. Navrotsky, C. M. Brown, P. M. Forster, Noble gas adsorption in copper trimesate, hkust-1: An experimental and computational study, J. Phys. Chem. C 117 (39) (2013) 20116-20126. doi:10.1021/jp408034u.

[36] K. V. Lawler, Z. Hulvey, P. M. Forster, Nanoporous metal formates for krypton/xenon separation, Chem. Commun. 49 (2013) 10959-10961. doi: 10.1039/C3CC44374D

[37] J. J. Perry, IV, S. L. Teich-McGoldrick, S. T. Meek, J. A. Greathouse, M. Haranczyk, M. D. Allendorf, Noble gas adsorption in metal-organic frameworks containing open metal sites, J. Phys. Chem. C 118 (22) (2014) 11685-11698. doi:10.1021/jp501495f.

[38] H. Wang, K. Yao, Z. Zhang, J. Jagiello, Q. Gong, Y. Han, J. Li, The first 590 example of commensurate adsorption of atomic gas in a mof and effective separation of xenon from other noble gases, Chem. Sci. 5 (2) (2014) 620624. doi:10.1039/C3SC52348A. 
[39] J. Liu, D. Strachan, P. Thallapally, Enhanced noble gas adsorption

q in ag@mof-74ni, Chem. Commun. 50 (2014) 466-468. doi:10.1039/ C3CC47777K.

[40] C. M. Simon, R. Mercado, S. K. Schnell, B. Smit, M. Haranczyk, What are the best materials to separate a xenon/krypton mixture?, Chem. Mater. Just Accepted (2015) 1. doi:10.1021/acs.chemmater.5b01475.

[41] E. R. Cooper, C. D. Andrews, P. S. Wheatley, P. B. Webb, P. Wormald, R. E. Morris, Ionic liquids and eutectic mixtures as solvent and template

(1) in synthesis of zeolite analogues, Nature 430 (2004) 1012-1016. doi:10. 1038/nature02860.

[42] A. Corma, F. Rey, J. Ruis, M. J. Sabater, S. Valencia, isupramolecular self-assembled molecules as organic directing agent for synthesis of zeolites, Nature 431 (2004) 287-290. doi:10.1038/nature02909

[43] J. A. Hriljac, High-pressure synchrotron x-ray powder diffraction studies of zeolites, Crystallogr. Rev. 12 (2) (2006) 181-193. doi:10.1080/ 08893110600772032

[44] A. Corma, M. E. Domine, L. Nemeth, S. Valencia, Al-free sn-beta zeolite as a catalyst for the selective reduction of carbonyl compounds (meerweinponndorf-verley reaction), J. Am. Chem. Soc. 124 (13) (2002) 3194-3195. doi:10.1021/ja012297m.

[45] D. Peng, D. Robinson, A new two-constant equation of state, Ind. Eng. Chem. Fundamen. 15 (1) (1976) 59-64. doi:10.1080/ 0892702031000065719

[46] N. Metropolis, A. W. Rosenbluth, M. N. Rosenbluth, A. H. Teller, E. Teller, Equation of state calculations by fast computing machines, J. Chem. Phys. 21 (1953) 1087-1092. doi:10.1063/1.1699114.

[47] M. P. Allen, D. J. Tildesley, Computer Simulations of Liquids, Clarendon, 620 Oxford, 1987. 
[48] D. Frenkel, B. Smit, Understanding Molecular Simulation, 2nd Edition, Academic Press, San Diego, 2002.

[49] A. Gupta, S. Chempath, M. Sanborn, L. Clark, R. Snurr, Object-oriented programming paradigms for molecular modeling, Mol. Simul. 29 (1) (2003) 29-46. doi:10.1080/0892702031000065719.

[50] J. a. A. P. Coutinho, E. H. Kontogeorgis, Georgios M. Stenby, Binary interaction parameters for nonpolar systems with cubic equations of state: a theoretical approach 1. co2/hydrocarbons using srk equation of state, Fluid Phase Equilib. 102 (1994) 31-60. doi:10.1016/0378-3812(94)87090-X.

[51] R. Q. Snurr, A. T. Bell, D. N. Theodorou, Prediction of adsorption of aromatic hydrocarbons in silicalite from grand canonical monte carlo simulations with biased insertions, J. Phys. Chem. 97 (1993) 13742-13752. doi:10.1021/j100153a051.

[52] R. Cracknell, P. Gordon, K. Gubbins, Influence of pore geometry on the design of microporous materials for methane storage, J. Phys. Chem. 97 (2) (1993) 494-499. doi:10.1021/j100104a036

[53] M. Jeffroy, E. Borissenko, A. Boutin, A. Di Lella, F. Porcher, M. Souhassou, C. Lecomte, A. H. Fuchs, Evidence of a framework induced cation redistribution upon water adsorption in cobalt exchanged $\mathrm{x}$ faujasite zeolite: A joint experimental and simulation study, Microporous Mesoporous Mater. 138 (1-3) (2011) 45-50. doi:10.1016/j.micromeso.2010.09.031.

[54] O. V. Dolomanovan, L. J. Bourhis, R. J. Gildea, J. A. K. Howard, H. Puschmann, Olex2: a complete structure solution, refinement and analysis program, J. Appl. Cryst. 42 (2009) 339-341. doi:10.1107/ S0021889808042726.

[55] P. Hohenberg, W. Kohn, Inhomogeneous electron gas, Phys. Rev. 136 (1964) B864. doi:10.1103/PhysRev.136.B864. 
[56] W. Kohn, L. J. Sham, Self-consistent equations including exchange and n correlation effects, Phys. Rev. 140 (1965) A1133. doi:10.1103/PhysRev. 140.A1133.

[57] P. E. Blöchl, Projector augmented-wave method, Phys. Rev. B 50 (1994) 17953. doi:10.1103/PhysRevB.50.17953.

[58] J. P. Perdew, K. Burke, M. Ernzerhof, Generalized gradient approximation made simple, Phys. Rev. Lett. 77 (1996) 3865. doi:10.1103/PhysRevLett. 77.3865

[59] S. Merlino, The crystal structure of wenkite, Acta Crystallogr B30 (1974) 1262-1266. doi:10.1107/S056774087400464X.

[60] P. Bai, M. Tsapatsis, J. I. Siepmann, Trappe-zeo: Transferable potentials for phase equilibria force field for all-silica zeolites, J. Phys. Chem. C 117 (46) (2013) 24375-24387. doi:10.1021/jp4074224.

[61] R. T. Cygan, J.-J. Liang, A. G. Kalinichev, Molecular models of hydroxide, oxyhydroxide, and clay phases and the development of a general force field, J. Phys. Chem. B 108 (4) (2004) 1255-1266. doi:10.1021/jp0363287.

[62] O. Talu, A. Myers, Reference potentials for adsorption of helium, argon, methane, and krypton in high-silica zeolites, Colloids Surf., A 187 (2001) 83-93. doi:10.1016/S0927-7757(01)00628-8.

[63] Crc handbook of chemistry and physics, 95th ed, 2014-2015 [cited Dec. 16, 2014].

URL http://www .hbcpnetbase.com

${ }_{670}^{6}$ [64] D. Wolf, P. Keblinski, S. R. Phillpot, J. Eggebrecht, Exact method for the simulation of coulombic systems by spherically truncated, pairwise $\mathrm{r}^{-1}$ (1) summation, J. Chem. Phys. 110 (17) (1999) 8254-8282. doi:10.1063/1. 478738 
[65] D. Zahn, B. Schilling, S. M. Kast, Enhancement of the wolf damped coulomb potential: Static, dynamic, and dielectric properties of liquid water from molecular simulation, J. Phys. Chem. B 106 (41) (2002) 1072510732. doi:10.1021/jp025949h

[66] H. Yu, W. F. van Gunsteren, Accounting for polarization in molecular simulation, Comput. Phys. Commun. 172 (2005) 69-85. doi:10.1016/j. cpc.2005.01.022.

[67] C. J. Fennell, J. D. Gezelter, Is the ewald summation still necessary? pairwise alternatives to the accepted standard for long-range electrostatics, J. Chem. Phys. 124 (2006) 234104. doi:10.1063/1.2206581.

[68] J. Yang, A.-M. Tian, H. Sun, Compass force field for 14 inorganic molecules, he, ne, ar, kr, xe, h2, o2, n2, no, co, co2, no2, cs2, and so2, in liquid phases, J. Phys. Chem. B 104 (2000) 4951-4957. doi:10.1021/jp992913p.

[69] R. L. Martin, M. Prabhat, D. D. Donofrio, J. A. Sethian, M. Haranczyk, Accelerating analysis of void space in porous materials on multicore and gpu platforms., Int. J. High Perform. Comput 26 (2012) 347-357. doi: $10.1177 / 1094342011431591$

[70] M. D. Foster, I. Rivin, M. M. Treacy, O. D. Friedrichs, A geometric solution to the largest-free-sphere problem in zeolite frameworks, Microporous

п Mesoporous Mater. 90 (1-3) (2006) 32-38. doi:10.1016/j.micromeso. 2005.08 .025

[71] K. V. Lawler, Z. Hulvey, P. M. Forster, On the importance of a precise crystal structure for simulating gas adsorption in nanoporous materials, Phys. Chem. Chem. Phys. 17 (2015) 18904-18907. doi:10.1039/C5CP01544H.

[72] D. G. Hay, H. Jaeger, G. W. West, Examination of the monoclinic/orthorhombic transition in silicalite using xrd and silicon nmr, J. 
[73] E. García-Pérez, J. B. Parra, C. O. Ania, D. Dubbeldam, T. J. Vlugt, J. M. Castillo, P. J. Merkling, S. Calero, Unraveling the argon adsorption processes in mfi-type zeolite, J. Phys. Chem. C 112 (27) (2008) 9976-9979. doi:10.1021/jp803753h.

[74] D. Banerjee, A. J. Cairns, J. Liu, R. K. Motkuri, S. K. Nune, C. A. Fernandez, R. Krishna, D. M. Strachan, P. K. Thallapally, Potential of metalorganic frameworks for separation of xenon and krypton, Acc. Chem. Res. 48 (2015) 211-219. doi:10.1021/ar5003126

[75] F. Karavias, A. Myers, Isosteric heats of multicomponent adsorption: Thermodynamics and computer simulations, Langmuir 7 (12) (1991) 3118-3126. doi:10.1021/la00060a035.

[76] A. Myers, P. Monson, Adsorption in porous materials at high pressure: 口 theory and experiment, Langmuir 18 (26) (2002) 10261-10273. doi:10. 1021/la026399h.

[77] K. Momma, F. Izumi, Vesta 3 for three-dimensional visualization of crystal, volumetric and morphology data, J. Appl. Cryst. 44 (2011) 1272-1276. doi:10.1107/S0021889811038970. 


\section{Tables}

Framework parameters for framework-fluid interactions

\begin{tabular}{ccccc} 
& LJ type & $\mathrm{R}_{0}(\AA)$ & $\varepsilon(\mathrm{K})$ & Charge $(\mathrm{e})$ \\
\hline $\mathrm{Si}^{a}$ & $12-6$ & 2.5817 & 22.0 & +1.500 \\
$\mathrm{O}^{a}$ & $12-6$ & 3.7041 & 53.0 & -0.750 \\
$\mathrm{H}^{b}$ & $12-6$ & 0.0 & 0.0 & +0.375
\end{tabular}

Noble Gas parameters for framework-fluid interactions

\begin{tabular}{cccccccc} 
& LJ type & $\mathrm{R}_{0}(\AA)$ & $\varepsilon(\mathrm{K})$ & $\alpha\left(\AA^{3}\right)$ & $\mathrm{T}_{c}(\mathrm{~K})$ & $\mathrm{P}_{c}(\mathrm{MPa})$ & $\mathrm{V}_{c}\left(\frac{c m^{3}}{\mathrm{~mol}}\right)$ \\
\hline $\mathrm{Ar}^{c}$ & $12-6$ & 3.8220 & 119.80 & 1.6411 & 150.687 & 4.863 & 75 \\
$\mathrm{Kr}^{d}$ & $12-6$ & 4.0768 & $180.00^{e}$ & 2.4844 & 209.48 & 5.525 & 91 \\
$\mathrm{Xe}^{d}$ & $12-6$ & 4.4449 & 230.30 & 4.0440 & 289.733 & 5.842 & 118
\end{tabular}

Noble Gas parameters for fluid-fluid interactions

\begin{tabular}{cccccccc} 
& LJ type & $\mathrm{R}_{0}(\AA)$ & $\varepsilon(\mathrm{K})$ & $\alpha\left(\AA^{3}\right)$ & $\mathrm{T}_{c}(\mathrm{~K})$ & $\mathrm{P}_{c}(\mathrm{MPa})$ & $\mathrm{V}_{c}\left(\frac{c m^{3}}{m o l}\right)$ \\
\hline $\mathrm{Kr}^{f}$ & $9-6$ & 4.3000 & 140.90 & 2.4844 & 209.48 & 5.525 & 91 \\
$\mathrm{Xe}^{f}$ & $9-6$ & 4.2600 & 196.26 & 4.0440 & 289.733 & 5.842 & 118
\end{tabular}

Table 1: Force Field and Critical Simulation Parameters. ${ }^{a}$ From TraPPE-zeo 60. ${ }^{b}$ From Clay-FF, charge lowered for charge neutrality. ${ }^{c}$ From Talu and Myers 62. ${ }^{d}$ Obtained from principle of corresponding states, critical parameters from the CRC 63]. ${ }^{e}$ Increased to match experiment. ${ }^{f}$ From COMPASS 68 . 


\begin{tabular}{|c||cc|cc|}
\hline \multicolumn{1}{|c||}{} & \multicolumn{2}{c|}{$298 \mathrm{~K} 10,000 \mathrm{mmHg}$} & \multicolumn{2}{c|}{$250 \mathrm{~K} 10,000 \mathrm{mmHg}$} \\
Code & $\mathrm{N}\left(\mathrm{cm}^{3} / \mathrm{g}\right)$ & $\mathrm{S}_{K r / X e}$ & $\mathrm{~N}\left(\mathrm{~cm}^{3} / \mathrm{g}\right)$ & $\mathrm{S}_{K r / X e}$ \\
\hline $\mathrm{ABW}$ & 1.42 & 48.44 & 5.84 & 39.85 \\
$\mathrm{ACO}$ & 76.58 & 1.68 & 134.68 & 1.30 \\
$\mathrm{AEN}$ & 2.46 & 9.12 & 10.09 & 8.97 \\
$\mathrm{APC}$ & 4.15 & 9.48 & 18.36 & 10.66 \\
$\mathrm{BIK}$ & 2.01 & 13.85 & 7.66 & 15.59 \\
$\mathrm{CHI}$ & 0.11 & 214.98 & 0.29 & 470.88 \\
$\mathrm{CZP}$ & 14.27 & 3.59 & 36.22 & 3.88 \\
$\mathrm{JBW}$ & 7.89 & 5.13 & 26.62 & 5.43 \\
LTJ & 2.30 & 11.41 & 10.34 & 12.94 \\
$\mathrm{MON}$ & 2.44 & 14.27 & 10.38 & 14.61 \\
$\mathrm{NAB}$ & 0.98 & 16.42 & 2.35 & 107.50 \\
$\mathrm{NAT}$ & 69.63 & 0.91 & 101.08 & 0.74 \\
NPO & 0.30 & 76.32 & 0.84 & 148.52 \\
NSI & 0.56 & 43.63 & 1.87 & 75.53 \\
PAR & 0.99 & 14.46 & 3.34 & 14.69 \\
RRO & 12.26 & 2.78 & 33.97 & 2.85 \\
RWR & 35.48 & 1.91 & 83.39 & 1.53 \\
VSV & 6.50 & 3.68 & 19.94 & 4.04 \\
WEI & 1.93 & 20.88 & 7.59 & 18.39 \\
YUG & 30.52 & 1.11 & 43.57 & 1.03 \\
\hline
\end{tabular}

Table 2: Simulated Total Quantities Adsorbed $\left(\mathrm{cm}^{3} / \mathrm{g}\right)$ and $\mathrm{Kr} / \mathrm{Xe}$ selectivities for initially $\mathrm{Kr}$ selective zeolite framework types calculated at $10,000 \mathrm{mmHg}$ at both $298 \mathrm{~K}$ and $250 \mathrm{~K}$. 


\section{Figure Captions}

720

Figure 2 Comparisons of experimental (solid) and simulated (dashed) Kr and Xe isotherms and heats of adsorption for BEA.

Figure 3 Comparisons of experimental (solid) and simulated (dashed) $\mathrm{Kr}$

Figure 4 Initial selectivities of a 90:10 $\mathrm{Xe} / \mathrm{Kr}$ mixture. The dashed line indicates a selectivity of 1 , below which the materials are selective for $\mathrm{Kr}$ instead of Xe.

Figure 5 High loading selectivities of a 90:10 Xe/Kr mixture. The dashed line indicates a selectivity of 1 , below which the materials are selective for $\mathrm{Kr}$ instead of Xe.

Figure 6 Initial selectivities of a 90:10 Xe/Kr mixture as a function of the difference in the Xe and $\mathrm{Kr}$ heats of adsorption. The dashed line indicates a selectivity of 1 , below which the materials are selective for $\mathrm{Kr}$ instead of Xe.

Figure 7 Xe loading density into ATN at $10 \mathrm{mmHg}$ and $298 \mathrm{~K}$.

Figure 8 Xe loading density into UFI at $10 \mathrm{mmHg}$ and $298 \mathrm{~K}$.

Figure 9 Selectivity vs. Percent Loading of a 90:10 Xe:Kr mixture into the top zeolites. 
(a)

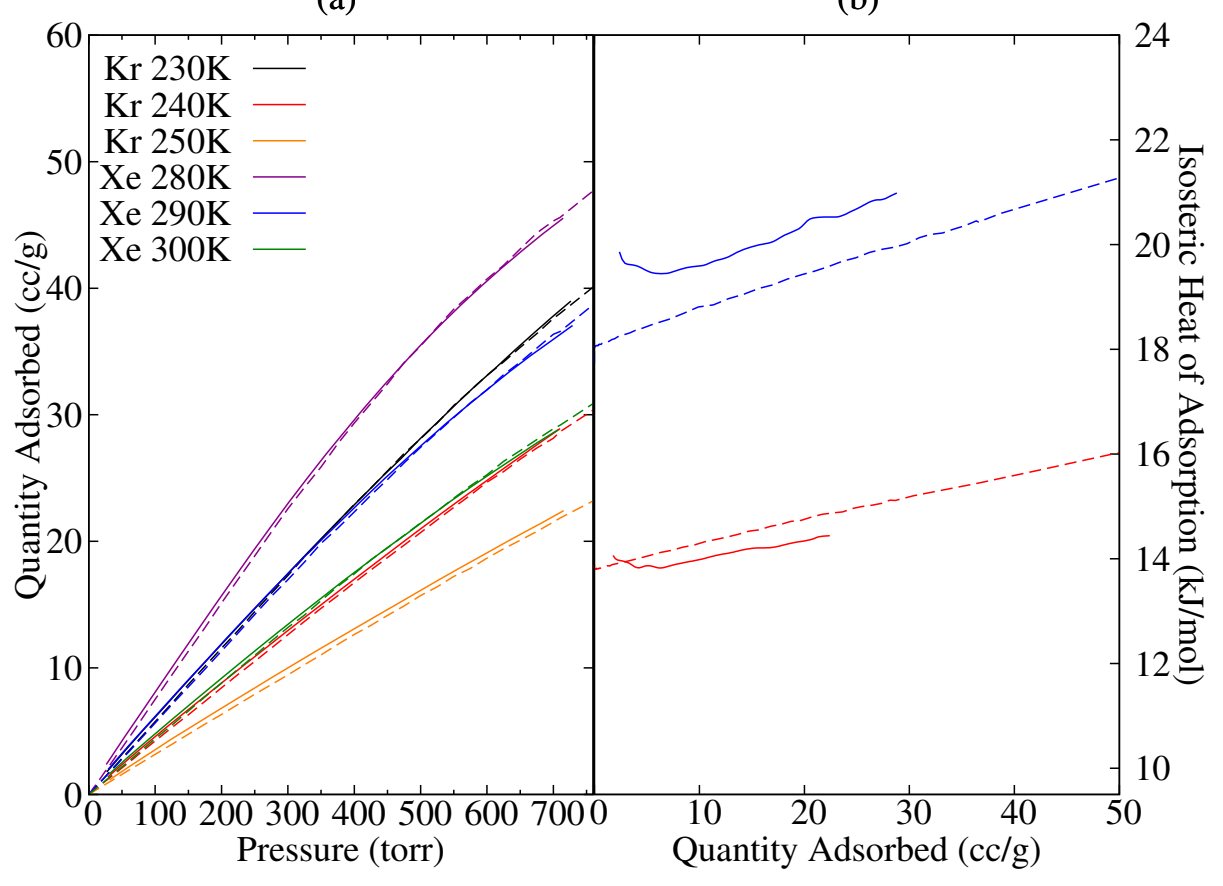

Figure 1: Comparisons of experimental (solid) and simulated (dashed) Kr and Xe isotherms and heats of adsorption for LTA.

(b) 
(a)

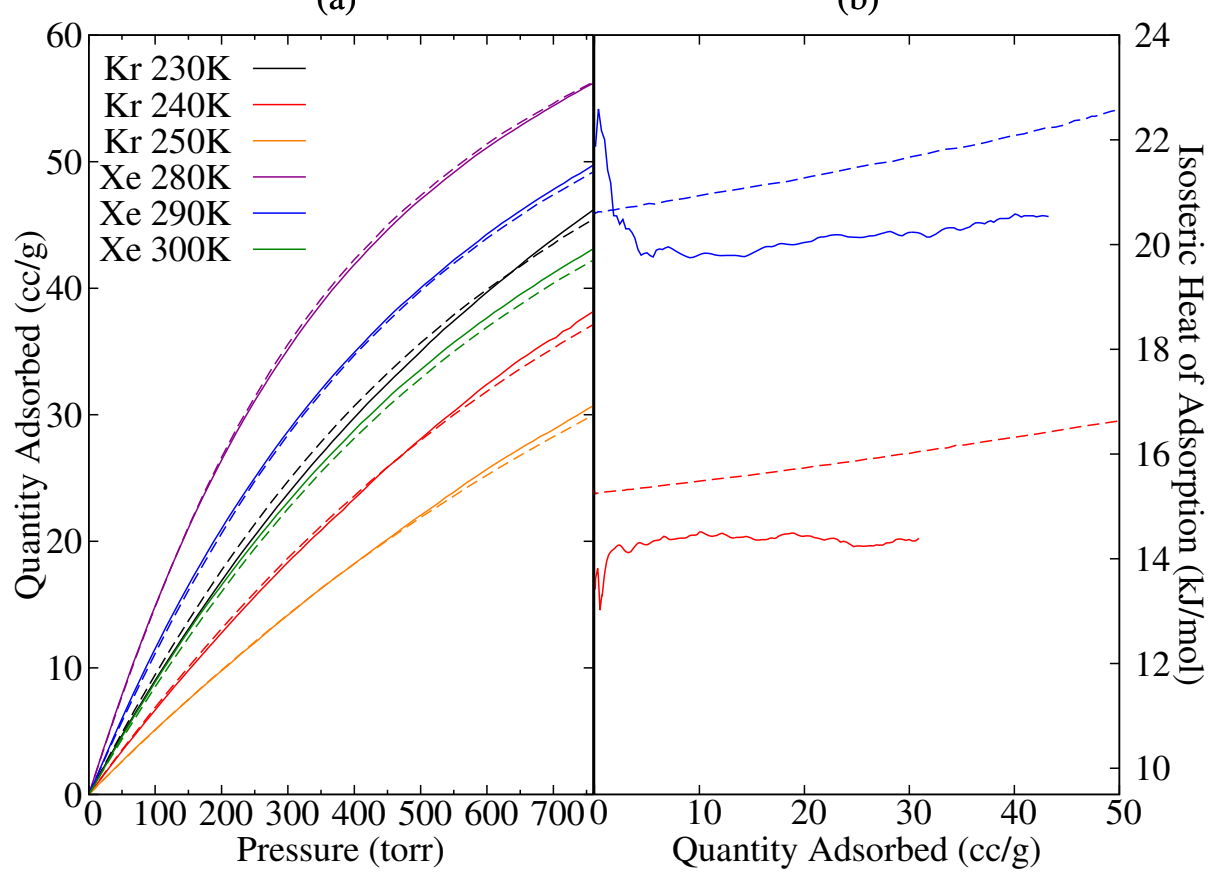

Figure 2: Comparisons of experimental (solid) and simulated (dashed) Kr and Xe isotherms and heats of adsorption for BEA.

(b) 
(a)

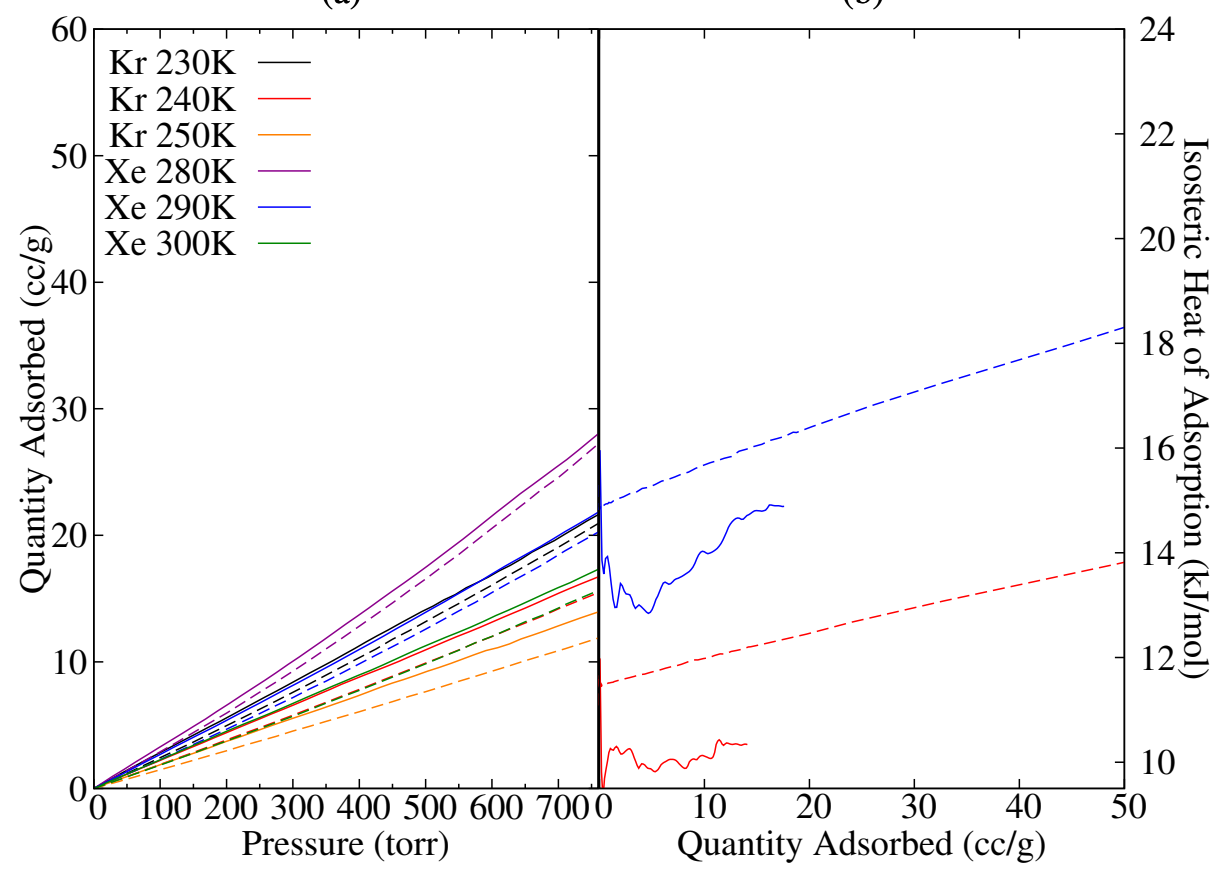

Figure 3: Comparisons of experimental (solid) and simulated (dashed) $\mathrm{Kr}$ and $\mathrm{Xe}$ isotherms and heats of adsorption for FAU.

(b) 


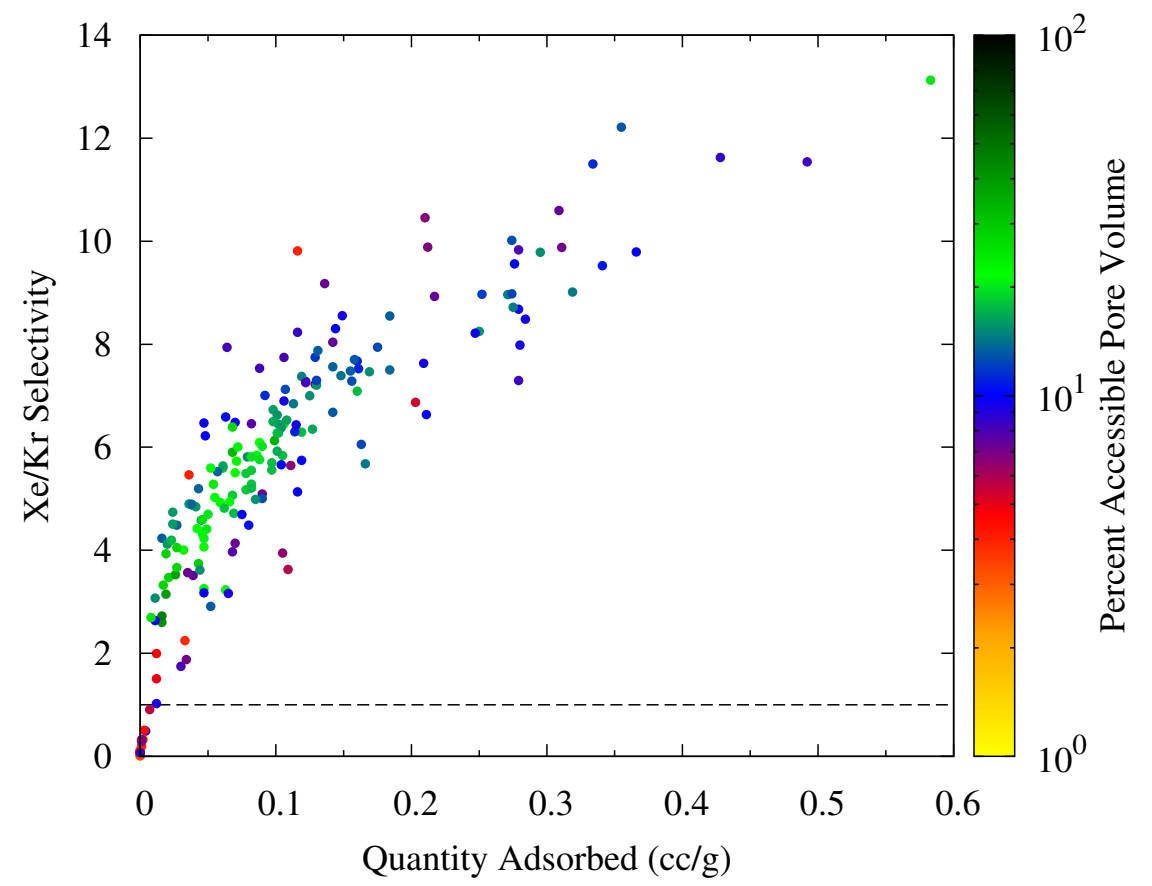

Figure 4: Initial selectivities of a 90:10 Xe/Kr mixture. The dashed line indicates a selectivity of 1 , below which the materials are selective for $\mathrm{Kr}$ instead of Xe. 


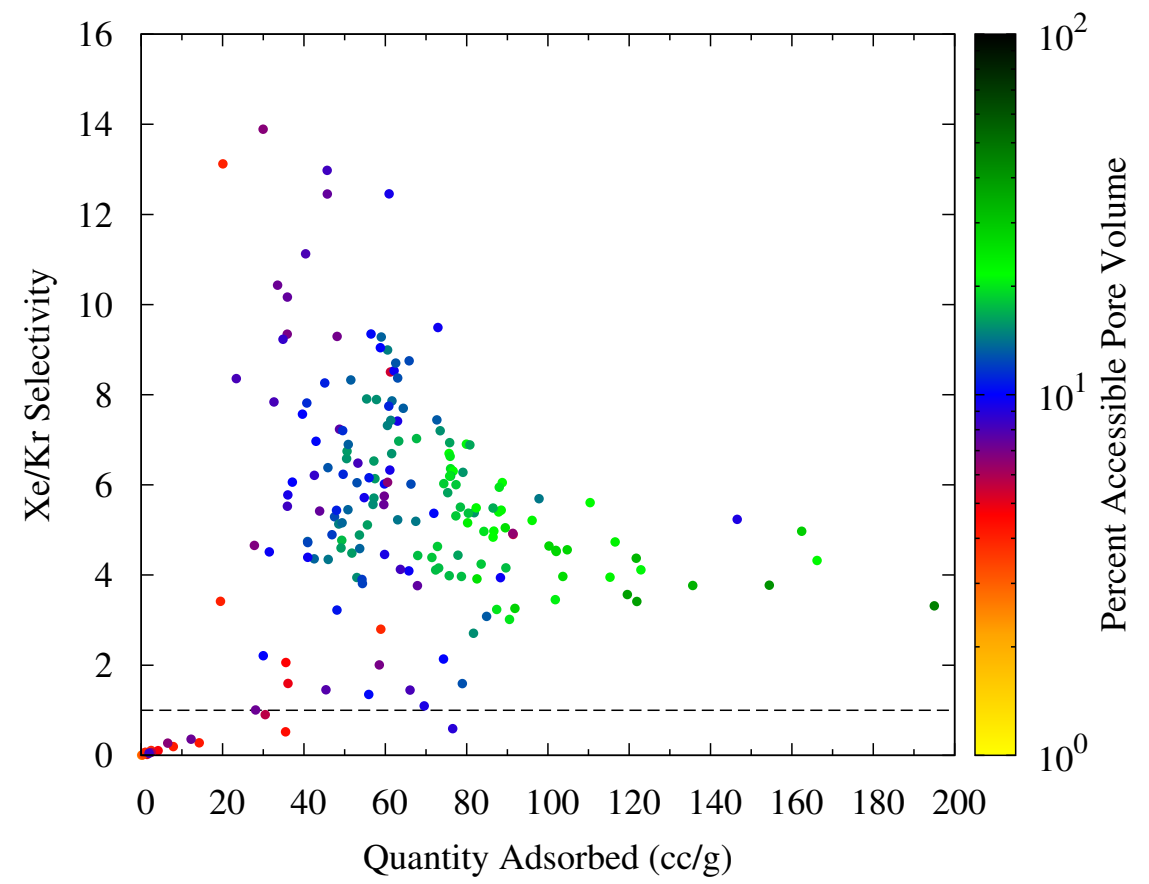

Figure 5: High loading selectivities of a 90:10 Xe/Kr mixture. The dashed line indicates a selectivity of 1 , below which the materials are selective for $\mathrm{Kr}$ instead of Xe. 


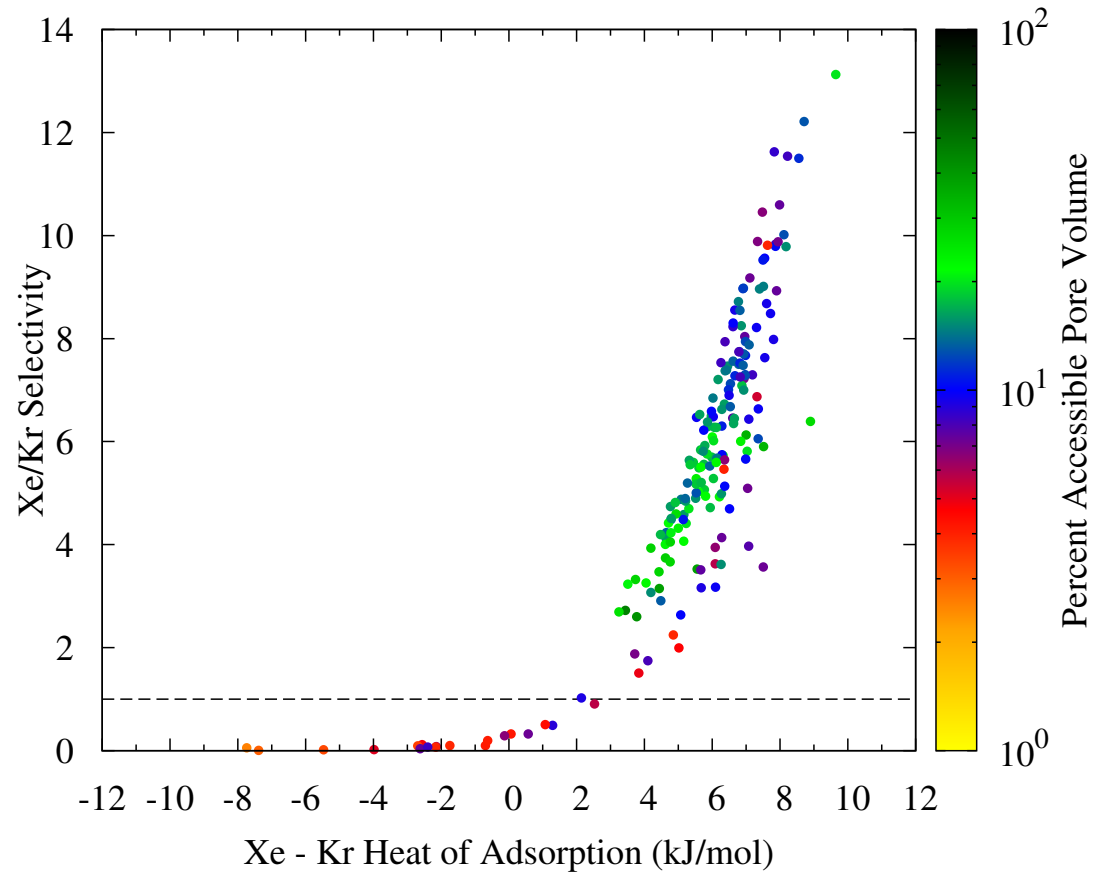

Figure 6: Initial selectivities of a 90:10 $\mathrm{Xe} / \mathrm{Kr}$ mixture as a function of the difference in the $\mathrm{Xe}$ and $\mathrm{Kr}$ heats of adsorption. The dashed line indicates a selectivity of 1, below which the materials are selective for $\mathrm{Kr}$ instead of Xe. 


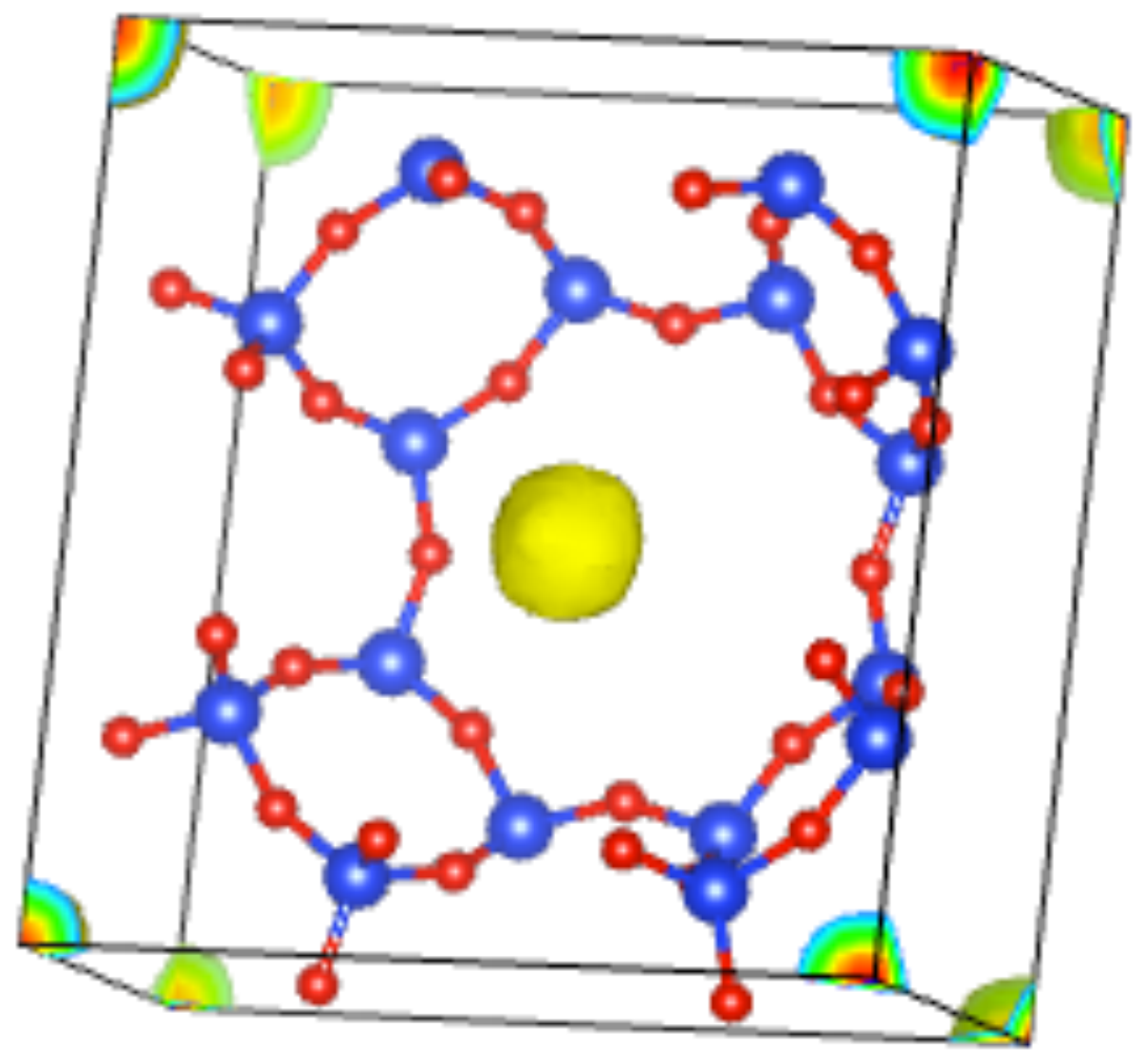

Figure 7: Xe loading density into ATN at $10 \mathrm{mmHg}$ and $298 \mathrm{~K}$. 


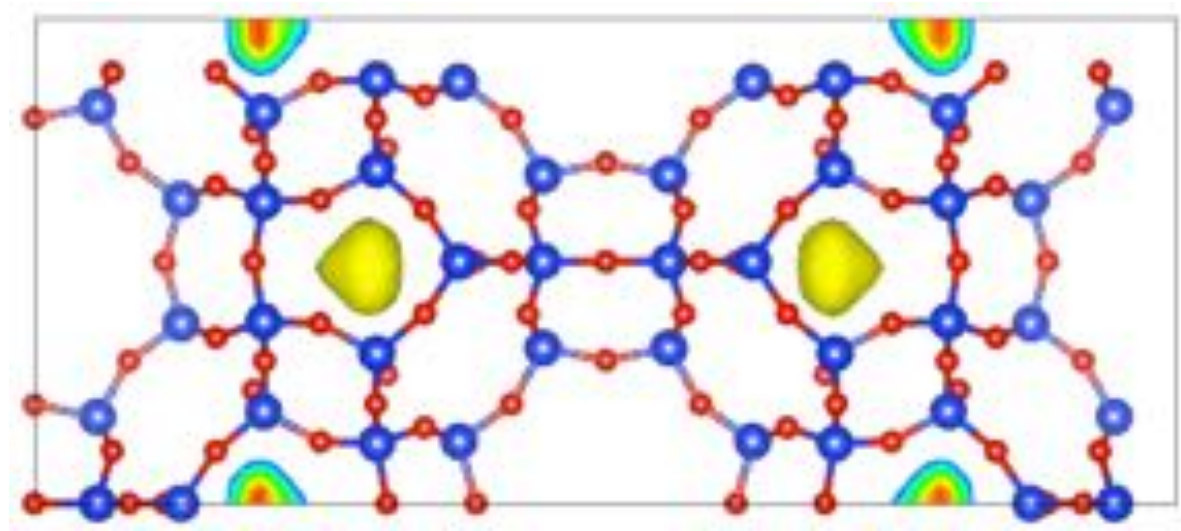

Figure 8: Xe loading density into UFI at $10 \mathrm{mmHg}$ and $298 \mathrm{~K}$. 


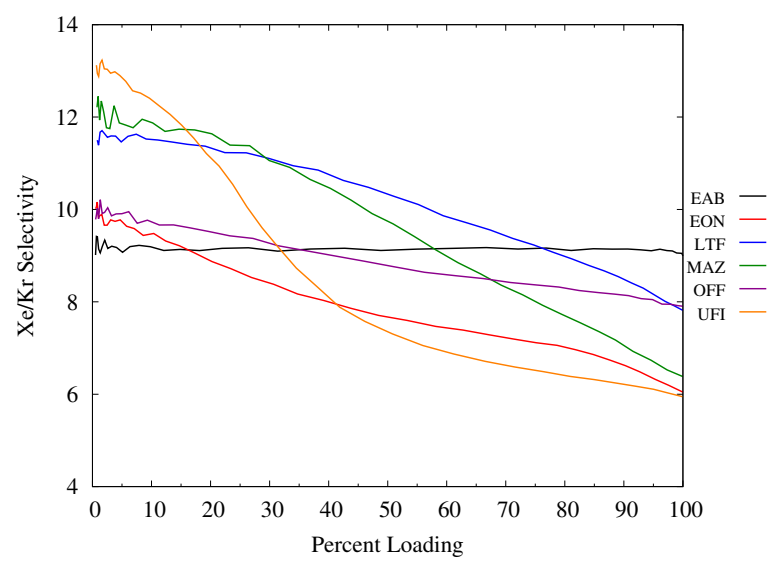

(a) Zeolites with small cages

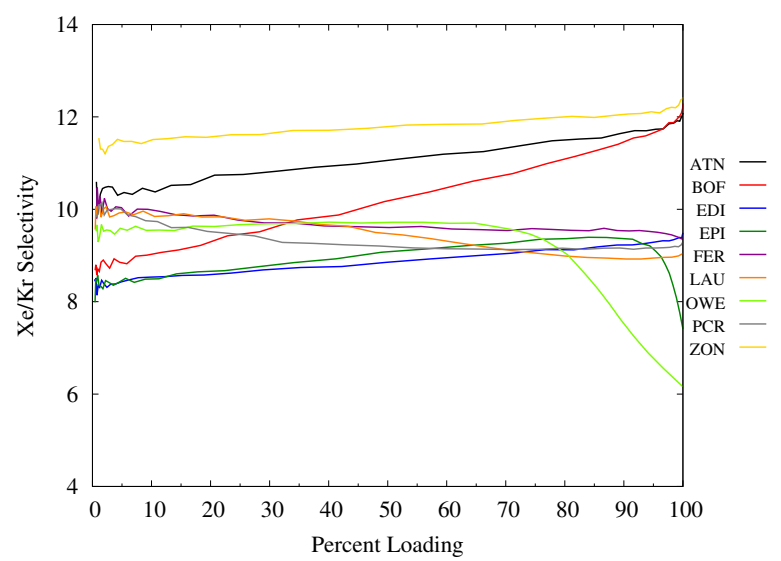

(b) Zeolites with channels and loading $\geq 45 \mathrm{~cm}^{3} / \mathrm{g}$

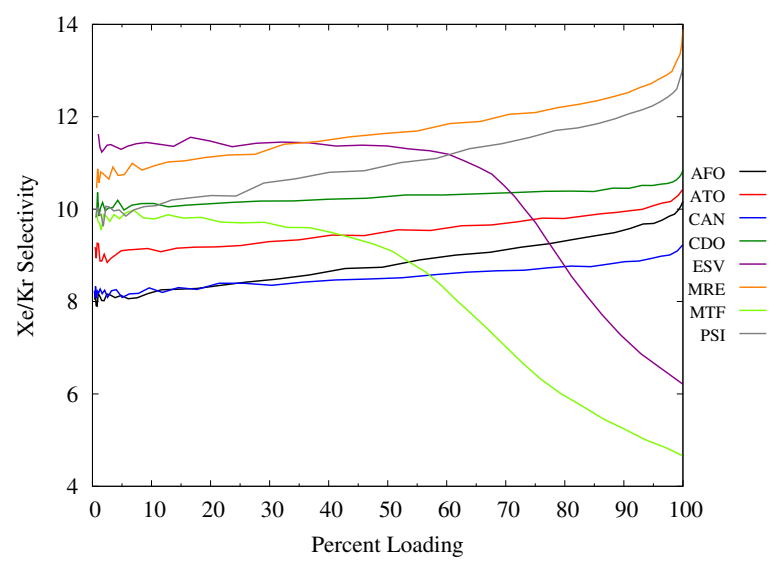

(c) Zeolites with channegsgand loading $\leq 45 \mathrm{~cm}^{3} / \mathrm{g}$

Figure 9: Selectivity vs. Percent Loading of a 90:10 Xe:Kr mixture into the top zeolites. 
